\title{
Relationship between metabolic hormones and ovulation of dominant follicle during the first follicular wave post-partum in high-producing dairy cows
}

\author{
Chiho Kawashima, Saori Fukihara, Mayumi Maeda, Etsushi Kaneko, Carlos Amaya Montoya ${ }^{1}$, \\ Motozumi Matsui ${ }^{1}$, Takashi Shimizu, Nobuyoshi Matsunaga ${ }^{2}$, Katsuya Kida ${ }^{3}$, Yoh-Ichi Miyake ${ }^{1}$, \\ Dieter Schams ${ }^{4}$ and Akio Miyamoto
}

Graduate School of Animal and Food Hygiene, ${ }^{1}$ Department of Clinical Veterinary Science, ${ }^{2}$ Department of Agricultural and Life Science, ${ }^{3}$ Field Centre of Animal Science and Agriculture, Obihiro University of Agriculture and Veterinary Medicine, Obihiro 080-8555, Japan and ${ }^{4} \mathrm{TU}$-Munich, Weihenstephan, Germany

Correspondence should be addressed to A Miyamoto; Email: akiomiya@obihiro.ac.jp

\begin{abstract}
Recent studies suggest that IGF-I is a crucial regulatory factor in follicular growth during early post-partum period. The aim of the present study was to determine in detail the changing profiles of metabolic and reproductive hormones in relation to ovulation of the dominant follicle (DF) of the first follicular wave post-partum in high-producing dairy cows. Plasma concentrations of related hormones in 22 multiparous Holstein cows were measured from 4 weeks pre-partum to 3 weeks post-partum, and the development of DF was observed with colour Doppler ultrasound. Thirteen cows showed ovulation by 15.2 days post-partum. Anovulatory cows showed higher GH and lower IGF-I levels than those in ovulatory cows during the peri-partum period. Each DF developed similarly, and a clear blood flow in the follicle wall was observed despite ovulation or anovulation. In addition, detailed endocrine profiles were analyzed in 9 out of the 22 cows. Five cows showed an increase in plasma oestradiol-17 $\beta$ (E2) with follicular growth followed by E2 peak, LH surge and ovulation. In these cows, plasma IGF-I concentrations remained high until 10 days post-partum followed by a gradual decrease. Subsequently, the insulin level increased together with the E2 peak towards ovulation. These profiles were not observed in anovulatory cows. In conclusion, our data strongly support the concept that IGF-I and insulin represent 'metabolic signals' of the resumption of ovarian function post-partum in high-producing dairy cows. Moreover, we provide the first visual evidence that both ovulatory and anovulatory DFs of the first follicular wave post-partum are similarly supplied with active blood flow.
\end{abstract}

Reproduction (2007) 133 155-163

\section{Introduction}

The negative energy balance early post-partum that is characterized by the loss of body weight and mobilization of body fat stores does not affect the first follicular wave post-partum (Beam \& Butler 1999). In fact, the medium-sized follicles appear 5 days after calving and grow into large follicles at 10 days post-partum in most dairy cows (Savio et al. 1990a, 1990b). However, almost a half of these follicles are not able to ovulate and become atretic or cystic. Most ovulations are observed within 3 weeks postpartum (Lamming \& Bulman 1976, Lucy et al. 1992b, Darwash et al. 1997). Our recent study showed that the recovery of ovarian function and subsequent reproductive performance in ovulatory cows within 3 weeks post-partum was superior to that of anovulatory cows (Kawashima et al. 2006). It is generally accepted that the cow with early resumption of the ovarian function has higher fertility (Staples et al. 1990, Senatore et al. 1996, Darwash et al. 1997). However, the factors that control the first ovulation post-partum have not been fully elucidated.

Insulin and insulin-like growth factor-I (IGF-I), metabolic hormones that are changed by feed intake, stimulate oestradiol-17 $\beta$ (E2) production in the granulosa cells (Gutierrez et al. 1997, Glister et al. 2001, Armstrong et al. 2003, Butler et al. 2004) and proliferation of follicular cells (Spicer et al. 1993, Spicer \& Stewart 1996). The growth of ovulatory follicles is regulated by metabolic hormones such as IGF-I or insulin and is susceptible to the endocrine and metabolic status during early lactation (Spicer et al. 1990, Lucy 
et al. 1992b). The liver-derived IGF-I is a factor that regulates the final maturation of the dominant follicle (DF) during the first follicular wave post-partum (Beam \& Butler 1998). The circulating IGF-I in ovulatory cows at the first follicular wave post-partum was higher than that in anovulatory cows (Beam \& Butler 1998).

Most of the above studies investigated a few metabolic factors during the first follicular wave post-partum. Therefore, the aim of the present study was to investigate the time-dependent relationship in detail among metabolic hormones, including IGF-I, growth hormone $(\mathrm{GH})$ and insulin, and metabolites such as glucose, nonesterified fatty acids (NEFA), total cholesterol (T-cho) and aspartate aminotransferase (AST), as well as the body condition score (BCS) and ovulation during the first follicular wave post-partum in a homogeneous herd at early lactation period in high-producing dairy cows. In addition, we used colour Doppler ultrasonography to monitor local blood flow during the growth of individual follicles.

\section{Materials and Methods}

Experimental procedures complied with the Guide for Care and Use of Agricultural Animals of Obihiro University.

\section{Animals}

The experiment was carried out in the Field Centre of Animal Science and Agriculture, Obihiro University of Agriculture and Veterinary Medicine. We used 22 multiparous Holstein cows that calved between October 2004 and April 2005. We collected samples from 4 weeks pre-partum to 3 weeks post-partum, with the period of 0-6 days after parturition regarded as a parturient week (week 0). Additionally, 9 out of the 22 cows that calved between February 2005 and April 2005 were used to observe the competence of the DF in detail; we collected blood samples ( 4 times/day) from the day of the appearance of a DF ( $8.5 \mathrm{~mm}$ in diameter) to 7 days after the first ovulation (ovulatory cows) or 20 days after calving (anovulatory cows). The cows were housed in a free-stall barn throughout the experimental period and offered a total mixed ration consisting of grass, corn silage and concentrate. Milking was performed twice daily (0600 and $1800 \mathrm{~h}$ ). The average 305-day milk yield was approximately $9700 \mathrm{~kg}$.

\section{Sampling}

BCS was assessed once a week during the experimental period by the same operator on a $0-5$ scale with 0.25 intervals, where $0=$ thin and $5=$ very fat (Ferguson et al. 1994).
Blood samples (serum) for biochemical analysis were obtained once a week by caudal venipuncture after measurement of BCS using unheparinized, silicone-coated $9 \mathrm{ml}$ tubes (Venoject, Autosep, Gel+Clot. Act., VP-AS109K; Terumo Corporation, Tokyo, Japan) and the tubes were coagulated for $30 \mathrm{~min}$ at $38{ }^{\circ} \mathrm{C}$ in an incubator. Blood samples (plasma) for hormonal analysis were obtained by caudal venipuncture twice weekly during the same period using sterile $10 \mathrm{ml}$ tubes containing $200 \mu \mathrm{l}$ stabilizer solution (0.3 M EDTA (pH 7.4), $1 \%$ acetyl salicylic acid). In addition, in 9 out of the 22 cows, we obtained blood samples 4 times/day at 6-h intervals for detection (presence or absence) of luteinizing hormone $(\mathrm{LH})$ surge. To minimize the stress of blood sampling, blood was drawn 2 times/day for detection of E2 peak and 1 time/day for profile of P4 and metabolic hormones. These tubes were centrifuged at 3000 r.p.m. for 20 min at $4{ }^{\circ} \mathrm{C}$, and the serum or plasma samples were kept at $-30{ }^{\circ} \mathrm{C}$ until biochemical and hormonal analyses.

Ovaries of all cows were scanned twice weekly from 7 days to 30 days after calving by transrectal ultrasonography using a colour Doppler ultrasound scanner (SSD-5500; Aloka Co., Tokyo, Japan) equipped with a 7.5 MHz convex transducer (UST-995-7.5; Aloka Co.). Follicles $\geq 5 \mathrm{~mm}$ were measured for maximum diameter and follicles $\geq 8.5 \mathrm{~mm}$ were regarded as DFs (Ginther et al. 2003). After morphological evaluation, the flow mode was activated for blood flow mapping and the presence or absence of blood flow was assessed for each follicle. Colour signals were used to generate images in which blood flow with a velocity higher than $2 \mathrm{~mm} / \mathrm{s}$ could be located as areas of colour within the follicle wall.

\section{Identification of ovulation during the first follicular wave post-partum}

When the P4 concentration in plasma was increased to more than $1 \mathrm{ng} / \mathrm{ml}$, the cow was confirmed as having returned to luteal activity (Stevenson \& Britt 1979). Furthermore, the first ovulation and luteal formation were identified using an ultrasound scanner equipped with a $7.5 \mathrm{MHz}$ convex transducer.

\section{Measurement of P4 and E2}

The P4 determination in plasma was performed by enzyme immunoassay (EIA) after extraction by diethyl ether, as described previously (Miyamoto et al. 1992), and the extraction efficiency was $93 \%$. The standard curve ranged from 0.05 to $50 \mathrm{ng} / \mathrm{ml}$, and the $50 \%$ of effective dose (ED50) of assay was $3.2 \mathrm{ng} / \mathrm{ml}$. The intraand interassay coefficient of variation $(\mathrm{CV})$ values averaged 6.7 and $7.2 \%$ respectively. The E2 determination in plasma was performed by EIA after extraction by diethyl ether as described previously (Acosta et al. 2000) and the extraction efficiency was $85 \%$. The standard 
curve ranged from 1.95 to $2000 \mathrm{pg} / \mathrm{ml}$, and the ED50 of assay was $5.2 \mathrm{pg} / \mathrm{ml}$. The intra- and interassay CV values averaged 6.7 and $8.7 \%$ respectively.

\section{Measurement of FSH, LH, GH, IGF-I and insulin}

The determination of plasma follicle-stimulating hormone (FSH), LH, GH, IGF-I and insulin was performed by EIA using the biotin-streptavidin amplification technique.

The FSH assay was performed as described previously (Watanabe et al. 1997). The standard curve for FSH ranged from 0.18 to $12 \mathrm{ng} / \mathrm{ml}$, and the ED50 of the assay was $1.7 \mathrm{ng} / \mathrm{ml}$. The intra- and interassay $\mathrm{CV}$ values averaged 8.3 and $14.6 \%$ respectively.

The LH assay was described previously in detail (Mutayoba et al. 1990). The standard curve for LH ranged from 0.09 to $50 \mathrm{ng} / \mathrm{ml}$, and the ED50 of the assay was $3.1 \mathrm{ng} / \mathrm{ml}$. The intra- and interassay CV values averaged 8.3 and $9.4 \%$ respectively.

The GH concentration was measured by the EIA as described by Roh et al. (1997), but with slight modification. A diluted rabbit antibody added to bovine GH $(100 \mu \mathrm{l}, \times 150000$, D Schams, TU-Munich, Weihenstephan, Germany) was distributed in all wells of a microplate coated with anti-rabbit $\gamma$-globulin antiserum, then incubated for $24 \mathrm{~h}$ at room temperature and the plate was decanted. After chicken serum diluted in assay buffer $(100 \mu \mathrm{l}, 1 \%)$ was added to each well, $15 \mu \mathrm{l} \mathrm{GH}$ standard (0.78-100 ng/ml, NIDDK-bGH, AFP-9984C) dissolved in assay buffer or plasma were incubated in wells for $24 \mathrm{~h}$. After decanting the plate, biotin-labelled $\mathrm{GH}$ was distributed in all wells and then incubated for $3 \mathrm{~h}$. Finally, colorimetric treatments were carried out. Intra- and interassay CV values were 8.1 and $8.5 \%$ respectively, and the ED50 in this assay system was $6.2 \mathrm{ng} / \mathrm{ml}$.

The total IGF-I determination in plasma was performed by the EIA after protein extraction by an acidethanol mixture $(87.5 \%$ ethanol and $12.5 \% 2 \mathrm{~N}$ hydrochloric acid; Daughaday et al. 1980) to obtain free IGF-I from binding protein. Thirty microlitres of human IGF-I standard (Roche; 0.39-50 ng/ml) dissolved in assay buffer or sample were added to each well coated with anti-rabbit $\gamma$-globulin antiserum. In addition, $100 \mu \mathrm{l}$ biotin-labelled hIGF-I $(\times 10000)$ and rabbit anti-hIGF-I $(\times 40000$, NIDDK, AFP18111298) diluted in assay buffer were distributed in all wells and then incubated for $72 \mathrm{~h}$ at $4{ }^{\circ} \mathrm{C}$. Finally, colorimetric treatments were carried out. Intra- and interassay CV values were 5.7 and $6.6 \%$ respectively, and the ED50 in this assay system was $2.5 \mathrm{ng} / \mathrm{ml}$.

The insulin determination was carried out by EIA. Insulin standard (Sigma) was diluted with charcoaltreated serum (insulin-free) during preparation. Thirty microlitres of insulin standard $(39-5000 \mathrm{pg} / \mathrm{ml})$ or plasma were added to each well coated with anti-guinea pig goat $\gamma$-globulin antiserum. In addition, $100 \mu \mathrm{l}$ antibovine guinea pig insulin $(\times 150000$, D Schams) dissolved in assay buffer were distributed in all wells and then incubated for $24 \mathrm{~h}$ at $4{ }^{\circ} \mathrm{C}$. After decanting the plates, $100 \mu \mathrm{l}$ biotin-labelled bovine insulin $(\times 50000)$ were distributed in all wells and then incubated for $2 \mathrm{~h}$ at $4{ }^{\circ} \mathrm{C}$. Finally, colorimetric treatments were carried out. Intra- and interassay CV values were 9.7 and $14.5 \%$ respectively, and the ED50 in this assay system was $800 \mathrm{pg} / \mathrm{ml}$.

\section{Biochemical analyses}

In each sample, the concentrations of glucose, NEFA, T-cho and AST were measured using a clinical chemistry automated analyser (TBA120FR; Toshiba Medical Systems Co., Tochigi, Japan).

\section{Statistical analyses}

All data from 22 cows was analyzed by repeated ANOVA. There was a tendency for a group $\times$ time interaction on plasma concentrations of E2 $(P=0.09)$ and plasma E2 concentrations changed over time in the ovulatory cows (time effect; $P<0.05$ ). Mean concentrations of E2 were calculated for each group and each sampling period, and significant differences were detected by Fisher's protected least significance difference test.

For other data, no significant interaction between group and time was observed. For all metabolites, metabolic hormones and BCS in 22 cows during the peri-partum period, mean concentrations for each cow were calculated for the pre- or post-partum periods. For the diameter of DFs and metabolic hormones in 22 cows at $1,1.5$ and 2 weeks post-partum, the mean diameter and mean concentrations during the sampling period were calculated and analyzed by repeated measures ANOVA. The significant differences between ovulatory and anovulatory cows were analyzed by Student's $t$-test.

In 5 cows which ovulated, we observed in detail their endocrine profiles. In 9 out of the 22 cows, we analyzed metabolic hormones before and after E2 peaks. We divided this into two phases: before E2 peak $(-10$ to -1 days relative to $E 2$ peak) and after $E 2$ peak ( $0-10$ days relative to $E 2$ peak), and the significant differences between the two phases were analyzed by paired $t$-test.

Results were expressed as means \pm s.E.M.; differences with $P<0.05$ were considered significant.

\section{Results}

Metabolites, BCS and metabolic hormones during the
peri-partum period related to the ovulation of the DF at
the first follicular wave post-partum

The numbers of cows showing ovulation and anovulation of a DF during the first post-partum follicular wave were 
$13(59.1 \%)$ and $9(40.9 \%)$ respectively. In ovulatory cows, the interval between calving and ovulation was $15.2 \pm$ 0.8 days, and after the first ovulation, cows had an ovarian cycle followed by more than 7 days of a luteal phase. The first month milk yield was $45.5 \pm 0.4 \mathrm{~kg} /$ day in ovulatory cows and $45.1 \pm 0.5 \mathrm{~kg} /$ day in anovulatory cows.

Figure 1 shows the change of metabolites, BCS and metabolic hormones during the peri-partum period. The serum concentration of glucose was not significantly different between the ovulatory and anovulatory cows during the pre-partum period. Thereafter, the serum glucose concentrations of the anovulatory cows were lower than those of the ovulatory cows during the postpartum period (ovulatory, $59.2 \pm 1.3$ vs anovulatory, $52.7 \pm 1.3 ; P<0.001)$. For BCS, there was no significant difference between ovulatory and anovulatory cows during the pre-partum period; however, BCS in ovulatory
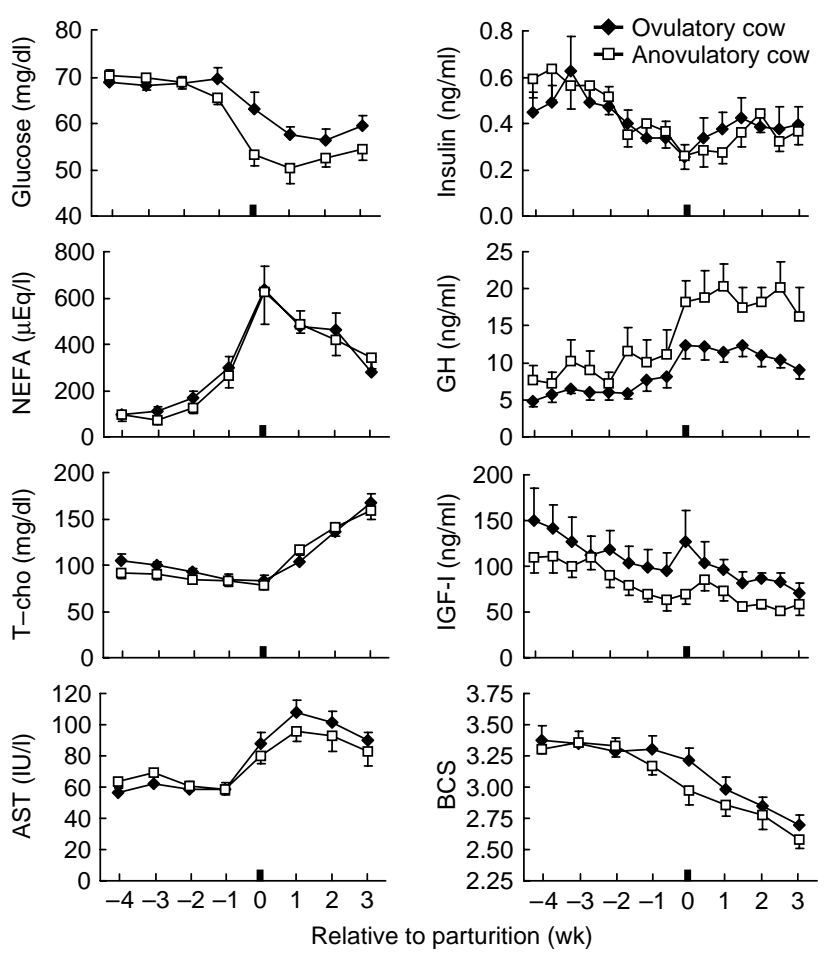

Figure 1 Metabolites, metabolic hormones and BCS from 4 weeks prepartum to 3 weeks post-partum for cows that developed either ovulatory $(n=13)$ or anovulatory $(n=9)$ dominant follicle during the first follicular wave post-partum (mean \pm s.E.M.; solid, ovulation; open, anovulation). The first sampling week after parturition was regarded as week 0 . The serum glucose concentrations in the anovulatory cows were lower than those in the ovulatory cows during the post-partum period $(P<0.001)$. BCS in ovulatory cows tended to be higher than that in anovulatory cows during the post-partum period ( $P=0.08)$. The plasma concentration of $\mathrm{GH}$ in anovulatory cows was higher than that in ovulatory cows during the peri-partum period (pre-partum, $P<0.01$; post-partum, $P<0.0001)$. On the other hand, the plasma concentration of IGF-I in the ovulatory cows was higher than that in the anovulatory cows during the peri-partum periods (pre-partum, $P<0.05$; postpartum, $P<0.01$ ). The concentrations of NEFA, T-cho, AST and insulin were similar between the ovulatory and the anovulatory cows during the period of study. cows tended to be higher than that in anovulatory cows during the post-partum period ( $P=0.08$; Fig. 1$)$. The serum concentrations of NEFA, T-cho and AST were similar between the ovulatory and the anovulatory cows during the period of study (Fig. 1).

The plasma concentration of insulin was not significantly different between the ovulatory and anovulatory cows during the pre- and post-partum periods. The plasma concentration of $\mathrm{GH}$ in anovulatory cows was higher than that of ovulatory cows during both pre- and post-partum periods (pre-partum, $P<0.01$; post-partum, $P<0.0001$; Fig. 1). On the other hand, the plasma concentration of IGF-I in ovulatory cows was higher than that of anovulatory cows during both pre- and postpartum periods (pre-partum, $P<0.05$; post-partum, $P<0.01$; Fig. 1).

\section{The function and morphology of DF during the first follicular wave post-partum, and metabolic status either ovulatory or anovulatory cows}

The DF of the first follicular wave appeared on day 7 post-partum, and the diameter of the DF was approximately $10 \mathrm{~mm}$ and blood flow in each follicle was observed by 14 days post-partum despite ovulation or anovulation (Fig. 2). In the ovulatory cows, a corpus luteum with blood flow was observed by 17 days postpartum (Fig. 2). On the other hand, the DF of anovulatory cows continued to grow maintaining identifiable blood flow (Fig. 2).

The plasma concentration of $\mathrm{FSH}$ did not differ between the ovulatory and anovulatory cows until 14 days post-partum (ovulation, $2.18 \pm 0.09 \mathrm{ng} / \mathrm{ml}$ vs anovulation, $2.05 \pm 0.09 \mathrm{ng} / \mathrm{ml})$. The ratio of the existence of the DF at the first scanning was $61.5 \%(8 / 13)$ in the ovulatory cows and $44.4 \%(4 / 9)$ in the anovulatory cows, and the diameter of the follicle at that time was not significantly different between the ovulatory and anovulatory cows (ovulation, $9.9 \pm 0.7 \mathrm{~mm}$ vs anovulation, $9.9 \pm 1.0 \mathrm{~mm}$ ).

The diameter of the DF had similar growth in both groups (time effect; $P<0.01$, Fig. 3 ) and did not differ between the ovulatory and the anovulatory cows during the period of study. The plasma concentrations of E2 in ovulatory cows was higher at 1.5 weeks post-partum than those at 1 and 2 weeks post-partum $(P<0.05$; Fig. 3), and higher than those in anovulatory cows at 1.5 weeks post-partum $(P<0.01$; Fig. 3$)$. However, there was no significant difference between the ovulatory and anovulatory cows at 2 weeks post-partum, because of the decrease of preovulatory E2 concentrations. In the ovulatory cows, plasma $\mathrm{GH}$ concentrations were lower $(P<0.01)$ and IGF-I concentrations were higher $(P<0.05)$ when compared with anovulatory cows, while the plasma insulin concentrations did not differ between the ovulatory and anovulatory cows during this period (Fig. 3). 
Ovulatory cow

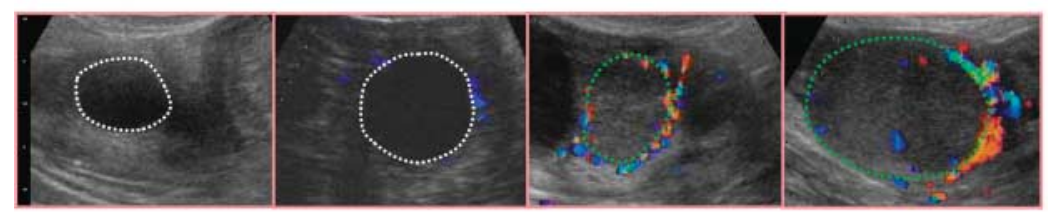

Anovulatory cow

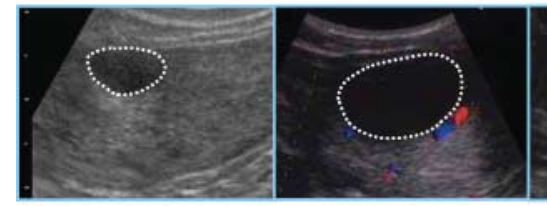

7 days pp

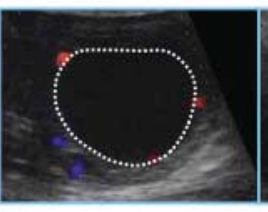

17 days $p p$

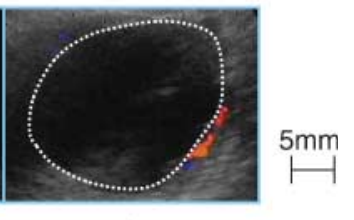

21 days $p p$
Figure 2 Representative images of dominant follicles during the first follicular wave postpartum of ovulatory and anovulatory cows. Red colour represents the blood flow towards the transducer, and blue indicates blood flow away from the transducer. The colour gain of the flow mode was set to detect the movement of at least $2 \mathrm{~mm} / \mathrm{s}$. Scale bar represents $5 \mathrm{~mm}$. The white dotted lines that delineate circles indicate the frame of the follicle and the green dotted lines that delineate circles indicate the frame of the corpus luteum.

\section{The metabolic endocrine factors related to ovulation of the $D F$ during the first follicular wave post-partum}

To observe the relationship between the growth of the DF and the endocrine and metabolic factors (E2, insulin, IGF-I and GH) in detail, 9 out of the 22 cows showing ovulation or anovulation of DFs during the first follicular wave post-partum were studied. The number of ovulatory cows was $5(55.6 \%)$, E2 peak could be confirmed on $16.0 \pm 1.1$ days post-partum, the interval between E2 peak and LH surge being approximately $21 \pm 7 \mathrm{~h}$, and the interval between calving and ovulation being $17.0 \pm$ 1.5 days. On the other hand, E2 peak and LH surge could not be confirmed in the anovulatory cows.

In the ovulated cows, E2 peak could be confirmed on $16.0 \pm 1.1$ days post-partum, and the interval between $\mathrm{E} 2$ peak and LH surge was approximately $21 \pm 7 \mathrm{~h}$ (Fig. 4). On the other hand, E2 peak and LH surge could not be confirmed in the anovulated cows (Fig. 4). In ovulated cows, insulin concentrations during and after the E2 peak period showed a strong tendency to be higher than those before the E2 peak $(P=0.06$; Table 1$)$. The $\mathrm{GH}$ concentrations from before until after the $\mathrm{E} 2$ peak did not change. However, plasma IGF-I remained high until 710 days post-partum, followed by a gradual decrease (Fig. 4). Therefore, IGF-I concentration during the after E2 peak was lower than that during the before E2 peak $(P<0.05$, Table 1$)$.

\section{Discussion}

The present study focused on the changes in metabolic hormones, such as IGF-I, GH and insulin that occurs during the peri-partum period in dairy cows and their relation to the occurrence of ovulation. The results suggest that the plasma concentration of IGF-I relates to the early growth of the ovulatory DF and insulin relates to the maturation and ovulation of the ovulatory DF at the first follicular wave post-partum.

Our results showed that higher plasma GH concentrations and lower glucose and IGF-I concentrations were the clear features in anovulatory cows during the pre-partum period compared with those of the ovulatory cows. Previous studies have shown that the expression of $\mathrm{GH}$ receptor $1 \mathrm{~A}$ and IGF-I mRNA in the liver declines at parturition, and $\mathrm{GH}$ concentrations are elevated during the post-partum period, because IGF-I concentrations decrease to low levels, reducing the negative feedback on GH (Kobayashi et al. 1999, Pushpakumara et al. 2003, Radcliff et al. 2003). The plasma IGF-I levels in the ovulatory cows at the first follicular wave post-partum were higher than those in the anovulatory cows (Beam \& Butler 1998). The high $\mathrm{GH}$ concentrations in the anovulatory cows in the present study with lower IGF-I concentrations during the peri-partum period may have caused $\mathrm{GH}$ insensitivity in the liver. These findings suggest that energy status, which reflects on GH, IGF-I and glucose levels, and ovulation are closely related to each other during the early post-partum period. However, in the present study, the metabolites such as NEFA, AST and T-cho did not differ between ovulatory and anovulatory cows during the peri-partum period, indicating that the lipid metabolism between these two groups was at similar levels despite the different $\mathrm{GH}$ levels between two groups. In the anovulatory cows, body fat stores might have already been reduced during the peri-partum period, resulting in lower BCS than that in ovulatory cows. Therefore, ovulatory cows may be able to handle better the negative energy balance after parturition when compared with anovulatory cows. The present study could not examine the exact feed intake and nutritional status, because all cows were provided with feed and water available ad libitum. Thus, further studies are necessary to investigate the effect of feed intake on metabolic hormones and on the maturation and ovulation of the first post-partum DF.

It was observed that the rate of follicular growth did not differ between the ovulatory and anovulatory cows during the post-partum period. The local blood flow was detected in DF of all cows despite ovulation or anovulation. Angiogenesis, the formation of new network of blood vessels, is essential for follicular 
development and ovulation (Yamada et al. 1994, Jiang et al. 2003). In addition, a recent report suggested that the angioprotein-tie system that acts on angiogenesis in concert with vascular endothelial growth factor controls the blood vessels to maintain active angiogenesis in developing bovine follicles (Hayashi et al. 2003). The maintenance of follicle vasculature and appropriate blood supply to the large follicles is essential for follicle dominance (Acosta et al. 2005). However, our results
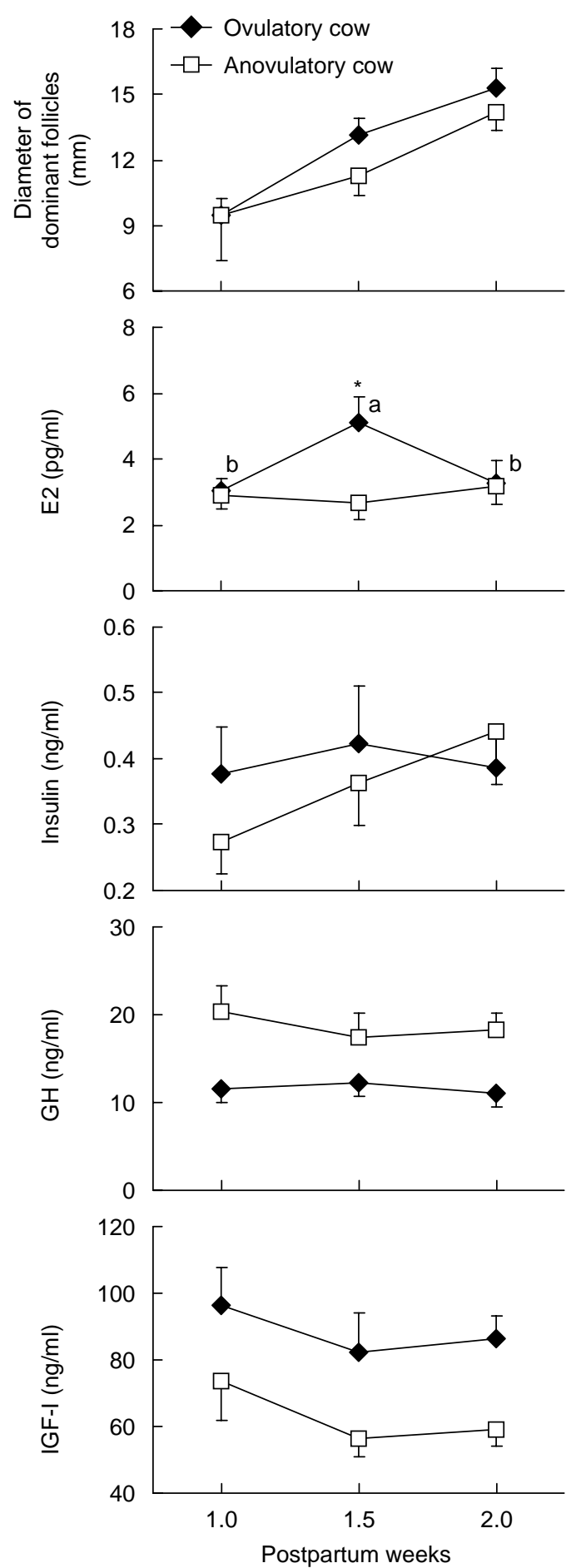

showed that an insufficient blood flow supply is not the cause of anovulation. The plasma E2 concentrations during this period increased only in the ovulatory cows, while those in the anovulatory cows did not, which are well consistent with previous reports (Beam \& Butler 1997, 1998). Thus, it is likely that an insufficient ability of the granulosa cells to secrete E2 is a determinant for anovulation rather than insufficient angiogenesis.

The plasma concentration of FSH did not differ between the ovulatory and anovulatory cows until 14 days post-partum. Our data confirmed the previous studies that FSH appears to be insensitive to metabolic status (Lamming et al. 1981, Beam \& Butler 1998). On the other hand, serum concentrations of IGF-I during the first follicular wave post-partum were reported to be at low levels in anovulatory dairy cows (Beam \& Butler 1998). In the present study, the plasma IGF-I remained elevated until 7-10 days post-partum, followed by a gradual decrease, whereas IGF-I in the anovulatory cows was kept at a low level throughout the post-partum period. The IGF-I stimulates steroidogenesis and the proliferation in follicular cells (Spicer et al. 1993, Spicer \& Stewart 1996), and the ratio of oestrogen to progesterone in follicular fluid was correlated positively with plasma IGF-I in lactating cows (Lucy et al. 1992a). In addition, IGF-I works with FSH synergically in promoting follicular development and E2 synthesis (Fortune et al. 2004). Thus, the data suggests that IGF-I is an important factor for the development of the DF to the maturation stage by amplifying the endocrine signal of FSH to upregulate E2 secretion from the future DF post-partum.

The present data suggested that plasma insulin level in the ovulatory cows increased together with E2 peak. In dairy cows, the serum insulin levels increase together with E2 during the development of the DF (Armstrong et al. 2003). Insulin has been shown to stimulate E2 production in the granulosa cells (Gutierrez et al. 1997, Glister et al. 2001). In addition, E2 secreted from a follicle also enhances insulin secretion from the

Figure 3 The function and morphology of the dominant follicle during the first follicular wave post-partum and metabolic status, which were data extracted from Fig. 1, either ovulatory $(n=13)$ or anovulatory $(n=9)$ cows at 1, 1.5 and 2 weeks post-partum (mean \pm s.E.M.; solid, ovulation; open, anovulation). ${ }^{*}$ Indicates differences of $P<0.01$ between the ovulatory and anovulatory cows at 1.5 weeks post-partum. $\mathrm{a}$ and $\mathrm{b}$ indicate differences of $P<0.05$ within ovulatory cows. The diameter of the dominant follicle was similar in both groups (time effect; $P<0.01$ ) and did not differ between the ovulatory and the anovulatory cows during the period of study. The plasma concentrations of E2 in ovulatory cows were higher than those in anovulatory cows at 1.5 weeks postpartum $(P<0.05)$; however, there were no significant differences between ovulatory and anovulatory cows at 2 weeks post-partum because of decrease of preovulatory E2 concentrations. In ovulatory cows, plasma GH concentrations were lower $(P<0.01)$ and IGF-I concentrations were higher $(P<0.05)$ when compared with anovulatory cows; however, the plasma insulin concentrations did not differ between the ovulatory and anovulatory cows during this period. 


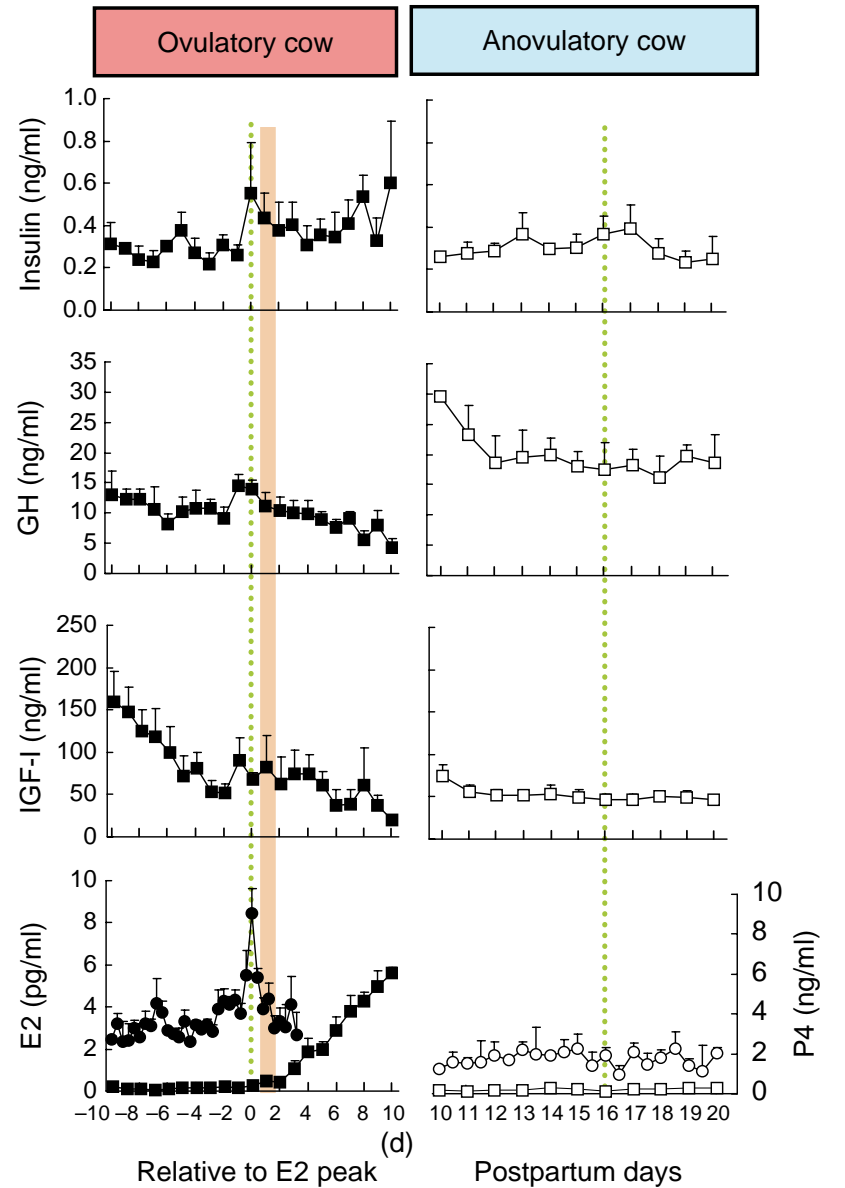

Figure 4 Daily representations of plasma concentrations of insulin, $\mathrm{GH}$, IGF-I and P4 in 9 out of the 22 cows. We obtained blood samples 4 times/day for detection (presence or absence) of LH surge, 2 times/day for detection of E2 peak and 1 time/day for profile of P4 and metabolic hormones. E2 concentrations are shown at 6-h intervals from 10 days before to 10 days after E2 peak in ovulated $(n=5)$ and from 10 days to 20 days post-partum in anovulated cows ( $n=4$; mean \pm s.E.M.). Insulin, GH, IGF-I and P4 concentrations are indicated by squares and E2 concentrations are indicated by circles; solid in ovulated cows ( $\mathbf{\square}$, and open in anovulated cows $(\square, \bigcirc)$. Dotted lines in both graphs indicate time of E2 peak in ovulated cows, and the orange vertical bar of the graph for ovulated cows indicates the range of $\mathrm{LH}$ surge $(21 \pm 7 \mathrm{~h}$ after E2 peak).

Table 1 The metabolic-endocrine factors between before and after E2 peak period in ovulatory cows.

\begin{tabular}{llcc}
\hline & \multicolumn{2}{c}{ Relative to E2 peak } & \\
\cline { 2 - 3 } & \multicolumn{1}{c}{ Before } & After & $\begin{array}{c}\text { Significance of } \\
\text { differences }\end{array}$ \\
\hline Insulin $(\mathrm{ng} / \mathrm{ml})$ & $0.29 \pm 0.03$ & $0.47 \pm 0.08$ & $P=0.06$ \\
$\mathrm{GH}(\mathrm{ng} / \mathrm{ml})$ & $11.7 \pm 1.5$ & $9.6 \pm 0.8$ & $\mathrm{NS}$ \\
$\mathrm{IGF}-1(\mathrm{ng} / \mathrm{ml})$ & $98.2 \pm 21.5$ & $61.1 \pm 13.7$ & $P<0.05$ \\
\hline
\end{tabular}

NS, not significant. Values are means \pm S.E.M. Data were divided into two phases which were before $E 2$ peak $(-10$ to -1 days relative to E2 peak) and after E2 peak (0-10 days relative to E2 peak). pancreas (Morimoto et al. 2001). These findings clearly indicate that plasma insulin and E2 from follicles positively interact with each other during the development of the DF. The increase in circulating insulin level by the feeding modification results in advanced first ovulation post-partum in the cow (Gong et al. 2002) and the increase in plasma $\mathrm{LH}$ concentration in heifer (McCann \& Hansel 1986). The LH pulse frequency was reported to be greater in ovulatory cows than in anovulatory cows (Lamming et al. 1981, Canfield \& Butler 1990, Jolly et al. 1995). Therefore, plasma insulin levels closely relate to the follicle growth and ovulation by regulating $\mathrm{LH}$ secretion. On the other hand, LH was not controlled by insulin infusion in early lactation cows (Butler et al. 2004). The energy status resulting in high insulin levels, but not directly insulin infusion, may induce the change of pulsatile $\mathrm{LH}$ release, follicle growth and ovulation. Consequently, the nutritional status which leads to the increase of insulin level together with E2 peak, is one of the key features of ovulatory cows. Undoubtedly, further studies are needed to characterize the factors responsible for the suboptimal $\mathrm{GnRH}$ and $\mathrm{LH}$ release after parturition in dairy cows.

As shown in Fig. 5, our results showed that the changes in the concentration of two metabolic hormones (IGF-I and insulin) may regulate the development of ovulatory follicle in the first follicular wave post-partum. In ovulatory cows, high IGF-I levels were maintained during the growth of DF, and then insulin levels increased together with the increase in E2 secretion from DF. These findings indicate that IGF-I is an essential factor for the growth of the DF, and insulin may stimulate the DF to mature and reach ovulation. Collectively, it is

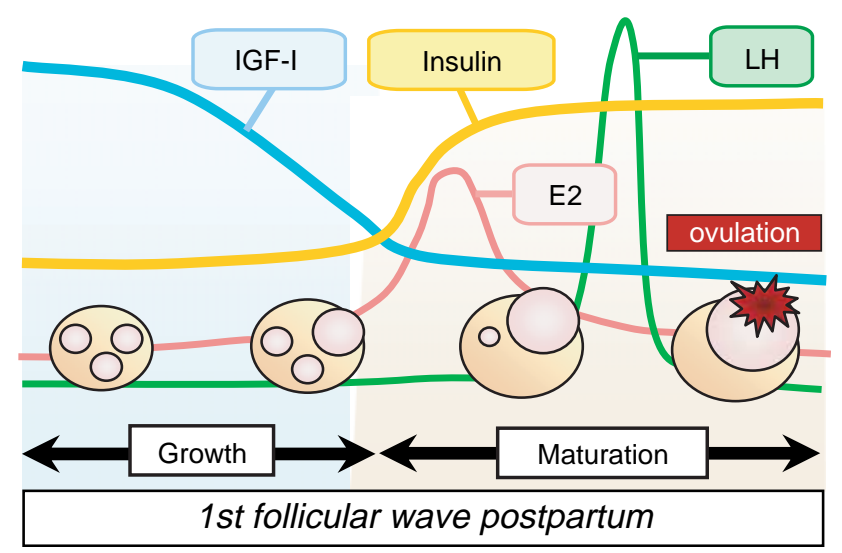

Figure 5 The summary of the results as a schematic representation of the growth and maturation of the dominant follicle at the first follicular wave post-partum. High IGF-I levels may stimulate the follicular cell function such as the steroidogenesis and the proliferation to appear healthy dominant follicle, and after that the levels decrease because of negative energy balance. Subsequently, E2 was secreted more. In contrast, the increase in insulin level together with E2 peak may enhance the maturation of the dominant follicle. Consequently, E2 enhanced by IGF-I induces LH surge and the dominant follicle reaches ovulation. 
suggested that the DF which is stimulated by high IGF-I levels during the first follicular wave post-partum, become ovulatory with the increase in E2 secretion, resulting in the occurrence of $\mathrm{LH}$ surge and ovulation.

In conclusion, the present study provides convincing evidence that IGF-I is an important factor for the development the DF during the first follicular development post-partum. After that, the increase in insulin level together with E2 peak may ensure the maturation and ovulation. Our findings strongly support the concept that IGF-I and insulin represent 'metabolic signals' for the resumption of ovarian function post-partum in highproducing dairy cows. Moreover, we provide the first visual evidence that both ovulatory and anovulatory DFs of the first follicular wave post-partum are similarly supplied with the active blood flow, suggesting that an insufficient angiogenesis is not a determinant for anovulation.

\section{Acknowledgements}

The authors thank Dr K Okuda, Okayama University, Japan, for P4 antiserum, and Dr Parlow, NIDDK, for the FSH, LH and GH standard, and IGF-I antiserum. This study was supported by the Grant-in-Aid for Scientific Research of the Japan Society for the Promotion of Science (JSPS); the 21st Century COE Programme (A-1) of the Ministry of Education, Culture, Sports, Science and Technology, Japan; Secure and Healthy Livestock Farming Project of the Ministry of Agriculture, Forestry and Fisheries; and the Japan Livestock Technology Association. C Kawashima and E Kaneko are supported by the COE programme. The authors declare that there is no conflict of interest that would prejudice the impartiality of this scientific work.

\section{References}

Acosta TJ, Ozawa T, Kobayashi S, Hayashi K, Ohtani M, Kraetzel WD, Sato K, Schams D \& Miyamoto A 2000 Periovulatory changes in the local release of vasoactive peptides, prostaglandin $\mathrm{F}_{2 \alpha}$ and steroid hormones from bovine mature follicles in vivo. Biology of Reproduction 63 1253-1261.

Acosta TJ, Hayashi KG, Matsui M \& Miyamoto A 2005 Changes in follicular vascularity during the first follicular wave in lactating cows. Journal of Reproduction and Development 52 273-280.

Armstrong DG, Gong JG \& Webb R 2003 Interactions between nutrition and ovarian activity in cattle: physiological, cellular and molecular mechanisms. Reproduction Supplement 61 403-414.

Beam SW \& Butler WR 1997 Energy balance and ovarian follicle development prior to the first ovulation postpartum in dairy cows receiving three levels of dietary fat. Biology of Reproduction $\mathbf{5 6}$ 133-142.

Beam SW \& Butler WR 1998 Energy balance, metabolic hormones, and early postpartum follicular development in dairy cows fed prilled lipid. Journal of Dairy Science 81 121-131.

Beam SW \& Butler WR 1999 Effects of energy balance on follicular development and first ovulation in postpartum dairy cows. Journal of Reproduction and Fertility. Supplement 54 411-424.

Butler ST, Pelton SH \& Butler WR 2004 Insulin increases 17 betaestradiol production by the dominant follicle of the first postpartum follicle wave in dairy cows. Reproduction 127 537-545.
Canfield RW \& Butler WR 1990 Energy balance and pulsatile LH secretion in early postpartum dairy cattle. Domestic Animal Endocrinology 7 323-330.

Darwash AO, Lamming GE \& Woolliams JA 1997 The phenotypic association between the interval to post-partum ovulation and traditional measures of fertility in dairy cattle. Animal Science 65 9-16.

Daughaday WH, Mariz IK \& Blethen SL 1980 Inhibition of access of bound somatomedin to membrane receptor and immunobinding sites: a comparison of radioreceptor and radioimmunoassay of somatomedin in native and acid-ethanol-extracted serum. Journal of Clinical Endocrinology and Metabolism 51 781-788.

Ferguson JD, Galligan DT \& Thomsen N 1994 Principal descriptors of body condition score in Holstein cows. Journal of Dairy Science 77 2695-2703.

Fortune JE, Rivera GM \& Yang MY 2004 Follicular development: the role of the follicular microenvironment in selection of the dominant follicle. Animal Reproduction Science 82-83 109-126.

Ginther OJ, Beg MA, Donadeu FX \& Bergfelt DR 2003 Mechanism of follicle deviation in monovular farm species. Animal Reproduction Science 78 239-257.

Glister C, Tannetta DS, Groome NP \& Knight PG 2001 Interactions between follicle-stimulating hormone and growth factors in modulating secretion of steroids and inhibin-related peptides by nonluteinized bovine granulosa cells. Biology of Reproduction $\mathbf{6 5}$ 1020-1028.

Gong JG, Lee WJ, Garnsworthy PC \& Webb R 2002 Effect of dietaryinduced increases in circulating insulin concentrations during the early postpartum period on reproductive function in dairy cows. Reproduction 123 419-427.

Gutierrez CG, Campbell BK \& Webb R 1997 Development of a longterm bovine granulosa cell culture system: induction and maintenance of estradiol production, response to follicle-stimulating hormone, and morphological characteristics. Biology of Reproduction 56 608-616.

Hayashi KG, Acosta TJ, Tetsuka M, Berisha B, Matsui M, Schams D, Ohtani M \& Miyamoto A 2003 Involvement of angiopoietin-tie system in bovine follicular development and atresia: messenger RNA expression in theca interna and effect on steroid secretion. Biology of Reproduction 69 2078-2084.

Jiang JY, Macchiarelli G, Tsang BK \& Sato E 2003 Capillary angiogenesis and degeneration in bovine ovarian antral follicles. Reproduction 125 211-223.

Jolly PD, McDougall S, Fitzpatrick LA, Macmillan KL \& Entwistle KW 1995 Physiological effects of undernutrition on postpartum anoestrus in cows. Journal of Reproduction and Fertility. Supplement $\mathbf{4 9}$ 477-492.

Kawashima C, Kaneko E, Amaya Montoya C, Matsui M, Yamagishi N, Matsunaga N, Ishii M, Kida K, Miyake Y-I \& Miyamoto A 2006 Relationship between the first ovulation within three weeks postpartum and subsequent ovarian cycles and fertility in high producing dairy cows. Journal of Reproduction and Development $\mathbf{5 2}$ 479-486.

Kobayashi Y, Boyd CK, Bracken CJ, Lamberson WR, Keisler DH \& Lucy MC 1999 Reduced growth hormone receptor (GHR) messenger ribonucleic acid in liver of periparturient cattle is caused by a specific down-regulation of GHR $1 \mathrm{~A}$ that is associated with decreased insulin-like growth factor I. Endocrinology $\mathbf{1 4 0}$ 3947-3954.

Lamming GE \& Bulman DC 1976 The use of milk progesterone radioimmunoassay in the diagnosis and treatment of subfertility in dairy cows. British Veterinary Journal 132 507-517.

Lamming GE, Wathes DC \& Peters AR 1981 Endocrine patterns of the post-partum cow. Journal of Reproduction and Fertility. Supplement 30 155-170.

Lucy MC, Beck J, Staples CR, Head HH, De La Sota RL \& Thatcher WW 1992a Follicular dynamics, plasma metabolites, hormones and 
insulin-like growth factor I (IGF-I) in lactating cows with positive or negative energy balance during the preovulatory period. Reproduction, Nutrition and Development 32 331-341.

Lucy MC, Staples CR, Thatcher WW, Erickson PS, Cleale RM, Firkins JL, Clark JH, Murphy MR \& Brodie BO 1992b Influence of diet composition, dry matter intake, milk production and fertility in dairy cows. Animal Production 54 323-331.

McCann JP \& Hansel W 1986 Relationships between insulin and glucose metabolism and pituitary-ovarian functions in fasted heifers. Biology of Reproduction 34 630-641.

Miyamoto A, Okuda K, Schweigert FJ \& Schams D 1992 Effects of basic fibroblast growth factor, transforming growth factor-beta and nerve growth factor on the secretory function of the bovine corpus luteum in vitro. Journal of Endocrinology 135 103-114.

Morimoto S, Fernandez-Mejia C, Romerro-Navarro G, MoralesPeza N \& Diaz-Sanchez V 2001 Insulin gene expression pattern in rat pancreas during the estrous cycle. Life Sciences 68 2979-2985.

Mutayoba B, Meyer H, Schams D \& Schallenberger E 1990 Development of a sensitive enzyme immunoassay for LH determination in bovine plasma using the streptavidin-biotin technique. Acta Endocrinologica (Copenhagen) 122 227-232.

Pushpakumara PG, Gardner NH, Reynolds CK, Beever DE \& Wathes DC 2003 Relationships between transition period diet, metabolic parameters and fertility in lactating dairy cows. Theriogenology 60 1165-1185.

Radcliff RP, McCormack BL, Crooker BA \& Lucy MC 2003 Plasma hormones and expression of growth hormone receptor and insulinlike growth factor-I mRNA in hepatic tissue of periparturient dairy cows. Journal of Dairy Science 86 3920-3926.

Roh S-G, Matsunaga N, Miyamoto A, Hidaka S \& Hidari H 1997 Competitive enzyme immunoassay for bovine growth hormone. Endocrine Journal 44 195-198.

Savio JD, Boland MP, Hynes N \& Roche JF 1990a Resumption of follicular activity in the early post-partum period of dairy cows. Journal of Reproduction and Fertility 88 569-579.

Savio JD, Boland MP \& Roche JF 1990b Development of dominant follicles and length of ovarian cycles in post-partum dairy cows. Journal of Reproduction and Fertility $\mathbf{8 8} 581-591$.
Senatore EM, Butler WR \& Oltenacu PA 1996 Relationship between energy balance and postpartum ovarian activity and fertility in first lactation dairy cows. Animal Science 62 17-23.

Spicer LJ \& Stewart RE 1996 Interactions among basic fibroblast growth factor, epidermal growth factor, insulin, and insulin-like growth factor-I (IGF-I) on cell numbers and steroidogenesis of bovine thecal cells: role of IGF-I receptors. Biology of Reproduction 54 255-263.

Spicer LJ, Tucker WB \& Adams GD 1990 Insulin-like growth factor-I in dairy cows: relationships among energy balance, body condition, ovarian activity, and estrous behavior. Journal of Dairy Science 73 929-937.

Spicer LJ, Alpizar E \& Echternkamp SE 1993 Effects of insulin, insulinlike growth factor I, and gonadotropins on bovine granulosa cell proliferation, progesterone production, estradiol production, and(or) insulin-like growth factor I production in vitro. Journal of Animal Science 71 1232-1241.

Staples CR, Thatcher WW \& Clark JH 1990 Relationship between ovarian activity and energy status during the early postpartum period of high producing dairy cows. Journal of Dairy Science 73 938-947.

Stevenson JS \& Britt JH 1979 Relationships among luteinizing hormone, estradiol, progesterone, glucocorticoids, milk yield, body weight and postpartum ovarian activity in Holstein cows. Journal of Animal Science 48 570-577.

Watanabe H, Miyamoto A \& Fukui Y 1997 A competitive enzymeimmunoassay for follicle-stimulating hormone in ovine plasma using biotin-streptavidine amplification. Reproduction, Fertility and Development 9 597-601.

Yamada O, Abe M, Takehana K, Iwasa K, Hiraga T \& Hiratsuka T 1994 Microvasculature of mature bovine follicles and its changes with ovulation. Journal of Reproduction and Development 40 307-315.

Received 29 May 2006

First decision 25 July 2006

Revised manuscript received 28 August 2006

Accepted 30 October 2006 